\title{
ELECCIONES, CONFLICTIVIDAD SOCIAL Y VIOLENCIA POLÍTICA EN LA ANDALUCÍA DEL FRENTE POPULAR
}

\author{
Diego Caro Cancela \\ UNIVERSIDAD DE CÁdIZ
}

\section{RESUMEN}

Este artículo hace una crítica de los principales mitos de la historiografía franquista, a través de lo que ocurre en la primavera de 1936 en Andalucía. Se demuestran las prácticas caciquiles que las derechas emplearon en las elecciones del Frente Popular, se cuestiona la tesis de la elevada conflictividad social en vísperas de la Guerra Civil y se atribuye la práctica de la violencia política a distintas causas.

Palabras Claves: historiografía, elecciones, Frente Popular, conflictividad social, anticlericalismo y violencia política.

\section{ABSTRACT}

This article makes a review of the main myths of the francoist historiography through what happens in the spring of 1936 in Andalusia. It proves the despotics practices that rightwind politics employed in the Front Popular elections it questions the theory of the high social unrest on the eve of Civil War and the political violence is attributed to many reasons.

Key Words: historiography, elections, Popular Front, social unrest, anticlericalism, political violence.

\section{INTRODUCCIÓN}

El régimen franquista surgido del golpe de Estado del 18 de julio de 1936, rápidamente encargó a sus propagandistas la creación de una serie de mitos históricos que permitieran justificar su violento nacimiento sobre la democracia republicana. De esta manera, to-

Véase, por ejemplo: GARRACHÓN CUESTA, Antonio.: De Africa a Cádiz y de Cádiz a la España Imperial. Por sendas de heroísmo, de justicia, de hermandad y de amor. Cádiz, Establecimiento Cerón, 1938. Se trata de una tendenciosa crónica periodística que, con estos prejuicios, recoge todo lo que ocurre en la ciudad de Cádiz, desde el 13 de febrero, vísperas de las elecciones del Frente Popular, hasta final del año 1936, ya en plena Guerra Civil. 
davía en plena Guerra Civil ${ }^{1}$, pero, sobre todo, nada más terminada ésta, los divulgadores de esta "historia oficial" del Régimen, dieron cuatro grandes “argumentos" para convertir lo que había comenzado como un simple golpe militar en un grandilocuente Glorioso Alzamiento $\mathrm{Nacional}^{2}$, todos ellos localizados cronológicamente en los primeros meses de 1936.

En primer lugar, de forma genérica se cuestionó la aptitud del pueblo español para disfrutar de un sistema democrático por ser "racialmente" violento y dado a las guerras fraticidas ${ }^{3}$. A continuación, se definieron como "ilegítimos" los poderes políticos emanados de las elecciones del 16 de febrero de 1936 por las "numerosas" irregularidades que acompañaron a la victoria de las izquierdas del Frente Popular. En tercer lugar, se dijo que la acción militar fue un golpe preventivo que vino a evitar la ejecución de un supuesto complot preparado por la Tercera Internacional y que tendría como último objetivo el establecimiento de un régimen comunista en España. Y, por último, estaría la incapacidad del Gobierno republicano para garantizar la vida y los bienes de las personas de "orden", sometidas a las acciones violentas de las izquierdas, que fue creciendo desde sus triunfo electoral y que culminó con el asesinato de Calvo Sotelo, líder parlamentario de la extrema derecha monárquica, considerado por sus partidarios como un auténtico "crimen de Estado"

Estos supuestos fueron los que una y otra vez se repitieron en la publicística que el franquismo generó durante varias décadas, en obras como la Historia de la Cruzada Española ${ }^{4}$, la Historia secreta de la Segunda República ${ }^{5}$, de Eduardo Comín Colomer o la Historia de la Segunda República Española de Joaquín Arrarás 6 , por citar algunas.

El tímido aperturismo practicado por el Régimen a partir de los años sesenta y la llegada a España -de forma clandestina- de otras historias de la Guerra Civil, como las publicadas por la editorial Ruedo Ibérico ${ }^{7}$, que regentaba un exiliado español en París, obligaron a las autoridades franquistas a "modernizar" su discurso sobre el conflicto bélico y sus causas, marginando los argumentos que ya estaban totalmente desacreditado ante la

2 REIG TAPIA, Alberto: "La justificación ideológica del Alzamiento", en: Violencia y terror. Estudios sobre la Guerra Civil española. Madrid, Akal, 1990, especialmente las páginas 23-28, tituladas “¿Pronunciamiento o Alzamiento?".

3 Incluso alguien como el prestigioso historiador TREVOR ROPER llegó a escribir lo siguiente, en el prólogo que hizo en 1967 a la segunda edición del libro de Burnett BOLLOTEN, The Grand Camouflage: "La Guerra Civil española debe verse como una guerra española, cuyos orígenes se encuentran en las condiciones españolas; y las condiciones españolas no son, y nunca han sido las mismas que las europeas: En: BOLLOTEN, Burnett.: $L a$ Guerra Civil española. Revolución y contrarrevolución. Madrid, Alianza Editorial, 1989, p. 19.

Sobre la polémica edición de este libro en su primera traducción al castellano y otras cuestiones que rodearon su elaboración y publicación, hay dos interesantes análisis: ARÓSTEGUI, Julio: "Burnett Bolloten y la Guerra Civil Española: la persistencia del Gran Engaño”, en: Historia Contemporánea, no 3 (1990), pp. 151-177, y: SOUTHWORTH, Herbert R. : "'El "gran camuflaje”: Julián Gorkin, Burnet Bolloten y la Guerra Civil española", en: PRESTON, Paul(ed.): La República asediada, Hostilidad internacional y conflictos internos durante la Guerra Civil. Barcelona, Península, 1999, pp. 265-310.

4 Empezó a publicarse a partir de 1939, en ocho volúmenes.

Madrid, 1954-1955, dos volúmenes.

Madrid, 1956-1963, cuatro volúmenes.

Citemos, por ejemplo, La guerra civil española, de Hugh THOMAS y, sobre todo, El mito de la Cruzada de Franco, de Herbert R. SOUTHWORTH, aparecido en 1963. Este último libro, en palabras de Paul PRESTON, "constituyó un derribo metódico de las falsedades sobre las que los franquistas habían edificado su historia". Vid. PRESTON, P.: "Guerra de palabras: los historiadores ante la guerra civil española", en: Revolución y guerra en España, 1931-1939. Madrid, Península, 1986, p. 17. 
opinión publica y la comunidad científica. Fue Ricardo de la Cierva el principal encargado de realizar esta tarea de "aggiornamento" de la historiografía oficial, tras ser nombrado por Fraga Iribarne, entonces ministro de Información y Turismo, jefe de la Sección de Estudios sobre la guerra de España creada en propio su departamento ${ }^{8}$.

Al frente de esta Sección, los primeros trabajos de Ricardo de la Cierva fueron dos recopilaciones bibliográficas y documentales: Cien libros básicos sobre la guerra de España $a^{9}$ y Los documentos de la primavera trágica. Análisis documental de los antecedentes inmediatos del 18 de julio de $1936^{10}$, volviéndose a reiterar en esta última algunos de los tópicos historiográficos del franquismo.

La muerte del dictador y la llegada de la democracia a partir del año 1975 permitieron que los españoles pudieran conocer -de primera mano- todas las versiones publicadas sobre el conflicto bélico, rompiéndose lo que parecía que era el monopolio que los hispanistas extranjeros habían ejercido sobre este tema. Nuevos historiadores vinculados a las Universidades españolas aportaron relevantes monografías -realizadas sobre fuentes inéditas y archivos extranjeros- que parecían que habían conseguido arrinconar definitivamente los tópicos historiográficos del primer franquismo. Sin embargo, el ascenso de la derecha política española, de la mano del Partido Popular en los años noventa del pasado siglo, ha puesto de actualidad una nueva historiografía sobre la Guerra Civil española, presuntamente "revisionista", pero cuyo único bagaje intelectual ha sido el de volver a rescatar los mismos planteamientos ya esbozado en los años cuarenta y cincuenta del pasado siglo por Comín Colomer y Joaquín Arrarás, esta vez para descargar - una y otra vez- sobre las izquierdas españolas, la responsabilidad del estallido de la Guerra, repartiendo culpas a "diestro y siniestro", como si el golpe del 18 de julio no hubiera sido más que la lógica reacción de "legítima defensa" de las derechas perseguidas por unas autoridades republicanas, que estaban instaladas en la anarquía y fuera de toda legalidad ${ }^{11}$.

Pues bien, lo que queremos realizar en las páginas que siguen es el análisis de lo que ocurre en la Andalucía de estos meses, la primavera de 1936, un período de la Segunda República sobre el que los historiadores han pasado muchas veces de puntilla o que ha sido observado con la óptica teleológica de la Guerra Civil. Todo ello para llegar a conclusiones radicalmente distintas de las que en su día establecieron y siguen predicando los apologetas de la Dictadura. Y lo queremos hacer a la luz de las numerosas aportaciones que ha proporcionado la reciente historiografía andaluza y también de la reinterpretación de los datos recogidos en algunas de las historias oficiales de la época.

De entrada, por ejemplo, lejos de asumir que la violencia era algo racialmente innato a los españoles, como dijeron en su día algunos intelectuales y también recogerían inte-

8 REIG TAPIA, Alberto.: Ideología e historia. Sobre la represión franquista y la guerra civil. Madrid, Akal, 1984, pp. 74-78. También: PRESTON, Paul: op. cit., pp. 20-21. Cuenta Alberto REIG que el origen de esta iniciativa vino de la lectura por parte de Fernando María Castiella, entonces ministro de Asuntos Exteriores, del libro de Gabriel JACKSON, La República española y la guerra civil,- aparecido en inglés en 1965 y traducido al castellano, en México, dos años después- y del debate que sus comentarios provocaron en un Consejo de Ministros.

9 Madrid, 1966.

10 Madrid, 1967

11 Un buen análisis crítico de esta reciente historiografía neofranquistaa, en: ESPINOSA MAESTRE, Francisco: El fenómeno revisionista o los fantasmas de la derecha española. Badajoz, Del Oeste ediciones, 2005, y REIG TAPIA, Alberto: “Quosque tandem Pío Moa?", en: htpp://www.pce.es/forodela memoria. También: MORADIELLOS, Enrique: 1936. Los mitos de la Guerra Civil. Barcelona, Península, 2004. 
resadamente los defensores de Franco, creemos que no se puede comprender en sus justos términos lo que ocurre en la Segunda República si no nos situamos en el contexto de lo que entonces estaba pasando en la Europa de entreguerras.

En segundo lugar, respecto a los resultados electorales, aunque ya hace más de tres décadas que el estudio dirigido por Javier Tusell desmintió la principal falacia levantada por los franquistas ${ }^{12}$, lo que hoy ya sabemos es lo contrario de lo que en su día escribieron los partidarios del golpe militar con evidente falsedad: que si hubo violencia, coacciones, amenazas y otras maniobras características del más rancio caciquismo para torcer la libre voluntad de los ciudadanos, en Andalucía, por lo menos, éstas procedieron de los grupos de derechas y de los agentes del Gobierno "portelista" interesados en el triunfo de sus candidaturas, por la coalición que formaron en casi todas las circunscripciones electorales.

De los planes de la Tercera Internacional para España y su conspiración, los trabajos de Herbert R. Southworth ${ }^{13}$ ya demostraron que eran unas burdas falsificaciones, algo que ha venido a confirmar el reciente libro de Antonio Elorza y Marta Bizcarrondo, dedicado al análisis de la política de la Internacional Comunista, en donde se afirma que la preocupación obsesiva de su Secretariado entre marzo y julio de 1936 fue, no la de provocar una ruptura revolucionaria, sino cómo parar un golpe militar de lo que llamaba la "reacción"14

Más cercanas a la realidad fueron las denuncias hechas sobre el deterioro de la convivencia ciudadana en la primavera de 1936. Claro que los responsables de esta situación no sólo fueron las izquierdas política y sindical, como interesadamente denunciaron los líderes derechistas en el Parlamento y de lo que rápidamente se hicieron eco sus portavoces periodísticos.

Como en toda estrategia de la tensión que se pone en marcha para justificar una acción armada de fuerza, una parte importante de la violencia política vino causada por la provocaciones de grupos fascistas y carlistas, metidos de llenos en los planes conspirativos y en la que cayeron los militantes de las organizaciones de la izquierda sindical y política, creando una dinámica infernal que sólo sirvió para dañar el prestigio de la propia República, por la incapacidad del Gobierno para frenarla. Pero vayamos por parte.

12 Las elecciones del Frente Popular. Madrid, Edicusa, 1971, dos tomos. Sin embargo, todavía hay algunos que siguen empeñados en sostenerla contra "viento y marea". Pongamos dos ejemplos. El primero es lo que afirma Vicente CARCEL ORTI en su libro La persecución religiosa en España durante la Segunda República (19311939). Madrid, Rialp', 1990. Aquí escribe: "Se trató en realidad de una victoria relativa de las izquierdas, que legítimamente no debía rebasar los 10 ó 12 diputados, pero que se transformó en triunfo rotundo gracias a la dejación del Gobierno Portela, que, prematuramente y contra la ley, puso el Estado en manos de las izquierdas, aprovechándose éstas para entrar a saco en las actas llegándose a falsificar muchas, sobre todo en Galicia, antes de que fuesen remitidas a Madrd". Y más recientemente, el adalid de esta historiografía neofranquista-Pío Moa- no ha tenido reparos en escribir que,"en febrero de 1936 llegó al poder, en unas elecciones virulentas y anómalas la coalición luego llamada Frente Popular(...).Algunos equiparan los levantamientos de 1934 y 1936. Craso error. El primero atacó a un Gobierno de derecha legítimo, y el segundo a uno ilegítimo. Pues el Gobierno del Frente Popular, salido de unas elecciones dudosas, se había deslegitimado a incumplir su deber más básico de salvaguardar la ley, amparando así el proceso revolucionario". Vid. VV.AA.: La Guerra Civil española mes a mes. Madrid, El Mundo, 2005, Tomo 3, pp. 203-205.

13 SOUTHWORTH, Herbert R. .: El mito de la Cruzada de Franco. Barcelona, Plaza y Janés, 1986(primera edición publicada en España), pp. 195-213. Más detalladamente, en: “Conspiración contra la República. Los "documentos secretos comunistas” fueron elaborados por Tomás Borrás, en: Historia 16, nº 26 (1978), pp. 41-57.

14 ELORZA, Antonio-BIZCARRONDO, Marta: Queridos camaradas. La Internacional Comunista y España, 1919-1939. Barcelona, Planeta, 1999, p. 279. El papel político del PCE habría de consistir en fortalecer tanto la unidad obrera, como el Frente Popular. 


\section{LA SEGUNDA REPÚBLICA EN EL CONTEXTO DE LA "GUERRA CIVIL EUROPEA"}

Fue Donald C. Watt uno de los primeros historiadores que empleó la expresión "guerra civil europea" para definir el conflicto que se planteó en todo el continente, nada más firmarse el armisticio en noviembre de 1918, cuando los conservadores y los demócratas defensores del Estado de Derecho afrontaron el desafío simultáneo de los nuevos reaccionarios de la derecha antiparlamentaria y de los revolucionarios de la izquierda antiburguesa ${ }^{15}$.

Este mismo término -"guerra civil europea"- es el que empleó Ernst Nolte para titular el libro en el que analiza el nuevo escenario que abrió la Primera Guerra Mundial y la Revolución Rusa en el continente, con nuevas ideologías políticas -el comunismo y el fascismo-novedosas estructuras partidistas y nuevos problemas sociales y económicos ${ }^{16}$.

Recientemente, Paul Preston también ha utilizado esta denominación para el trabajo en el que analiza la política y las relaciones internacionales entre 1914 y 1945 y en el que, según él, la guerra civil española, "no sería sino la última y más encarnizada batalla de una guerra civil europea que se había librado desde el triunfo bolchevique de 1917"17. Y es que lo que caracteriza a este período de entreguerras son los temores de la derecha más reaccionaria a la amenaza del bolchevismo y las esperanzas de la izquierda en un mundo nuevo, dando lugar a una lucha violenta y continuada que no se limitó a las fronteras nacionales, sino que desbordando éstas, prácticamente se va a extender por todos los países, adoptando sus propias peculiaridades en cada uno de ellos.

Enrique Moradiellos también ha situado en la resaca de la "Gran Guerra" los orígenes de la gran inestabilidad política y social que padece la Europa de los años veinte y treinta. Una situación crítica, con nuevos escenarios políticos, sociales y económicos que harían imposible el retorno al orden anterior y que van a dar lugar a la aparición de tres proyectos políticos alternativos para hacer frente a la crisis, cada uno subordinado a los intereses de la clase o el grupo social que lo lidera:

"El proyecto reformista se basaba en una profundización del orden liberal tradicional con el objetivo de estabilizar la nueva situación mediante una democratización del sistema político y social que hiciera compatible el normal funcionamiento de la economía capitalista con la participación obrera en la gestión del Estado. Por su parte, la alternativa reaccionaria, en su faceta fascista o fascistizante, pretendía acabar con el peligro revolucionario mediante la anulación de la autonomía de la clase obrera y su supeditación a un programa de integración nacionalista de carácter totalitario o autoritario. Por último, el modelo revolucionario de matriz obrera implicaba la destrucción del régimen económico capita-

15 WATT,D. C.: "The Nature of the European Civil War, 1919-1939", capítulo primero de su obra Too Serious to the Second World War. Londres, 1975, citado en: MORADIELLOS, Enrique: "La Guerra de España. La Guerra Civil y el conflicto europeo", en: Claves de la Razón Práctica, $n^{\circ} 78$ (1997), p. 50

16 NOLTE, Ernst: La guerra civil europea, 1917-1945. Nacionalsocialismo y bolchevismo. México, Fondo de Cultura Económica, 1994. La primera edición en alemán

17 PRESTON, Paul : "La guerra civil europea (1914-1945)", en: Claves de la razón práctica, no 53 (1995), pp. 222. 
lista y su sustitución por un régimen comunista ortodoxo o por otro régimen colectivista y vagamente libertario" $"$.

Pues bien, lo original de los cinco años que duró la experiencia democrática de la Segunda República española fue la sucesiva aplicación de dos de estos proyectos, el reformista y el reaccionario. De esta manera, lo que caracteriza la política del primer bienio republicano fue la ejecución parcial del proyecto reformista, gracias a la coalición de los grupos políticos representativos de la pequeña burguesía republicana con parte de la clase obrera organizada por la UGT y el PSOE.

El fracaso de estos partidos en las elecciones de 1933 dio paso al proyecto reaccionario que encarnaban el Partido Radical y la CEDA, eso sí, todavía sin el componente de aniquilación física de las organizaciones obreras de clase que ya venían practicando los fascismos italiano y alemán y que llegará más tarde con el golpe militar del 18 de julio de 1936. Finalmente, la victoria del Frente Popular paralizaría por pocos meses este proyecto reaccionario, devolviendo a la práctica política el proyecto reformista, cada vez más desbordado por el radicalismo de las organizaciones obreras revolucionarias.

En este análisis de la política republicana siguiendo los parámetros de lo que ocurre en la Europa de los años treinta, la singularidad española se da en el protagonista del proyecto revolucionario, que aquí no lo representa un débil Partido Comunista, ni un dividido Partido Socialista, sino el sindicato CNT, que liderado por los sectores más radicales del anarquismo peninsular intentará llevarlo a la práctica a través de las huelgas generales insurreccionales de los años 1932 y 1933.

\section{EL TRIUNFO DEL FRENTE POPULAR EN ANDALUCÍA}

Como ya es sabido, fue el rechazo del presidente de la República al lider de la CEDA, Gil Robles, para que encabezara un nuevo Gobierno, tras el hundimiento del Partido Radical, lo que abrió una tercera fase en la política republicana, con una nueva disolución anticipada de las Cortes y la convocatoria de elecciones para el 16 de febrero de 1936.

Con muchos líderes obreros encarcelados desde la Revolución de Octubre del 34, con escasos órganos periodísticos que defendieran abiertamente sus posiciones y con el Gobierno amparando sus propios candidatos, incluyéndolos en las listas derechistas, la campaña electoral estuvo marcada por las presiones de éstas y los gobernadores civiles para inclinar en favor de sus candidaturas los resultados de las elecciones. En Jerez de la Frontera, por ejemplo, llegaría a ser detenido todo el comité electoral del Frente Popular y el alcalde cedista -contando con la connivencia del gobernador civil- estuvo cambiando hasta última hora la ubicación de las mesas electorales de la campiña para confundir a los cientos de jornaleros que en ellas estaban censados ${ }^{19}$. Francisco Moreno Gómez, por otra parte, ha contado cómo en Córdoba la convocatoria de las elecciones fue inmediatamen-

18 MORADIELLOS, E.: op. cit., p. 51. Este mismo tipo de análisis es el que ya había realizado Gregory M. LUEBBERT, dando importancia a las alianzas de clase y a la irrupción de la clase obrera organizada en la vida pública. Vid. Liberalismo, fascismo y socialdemocracia. Clases sociales y orígenes políticos de los regímenes de la Europa de entreguerras. Zaragoza, Prensas Universitarias de Zaragoza, 1997.

19 CARO CANCELA, Diego: Violencia política y luchas sociales. La Segunda República en Jerez de la Frontera, 1931-1936. Jerez, Ayuntamiento de Jerez, 2001, pp. 422-424. 
te seguida por la destitución y reorganización de numerosos Ayuntamientos de la provincia, en favor de los seguidores "centristas" de Alcalá Zamora y Portela y de la propia CEDA, sin que faltaran denuncias irónicas sobre la compra de votos por parte de uno de los candidatos de la coalición contrarrevolucionaria ${ }^{20}$.

Lo mismo ocurría en la provincia de Jaén, donde con la ayuda de las comisiones gestoras, la policía municipal y la Guardia Civil, "los patronos agrarios instigaron una verdadera multitud de amenazas dirigidas contra los trabajadores agrícolas, quienes eran insultados, amedrentados, castigados, detenidos e incluso apaleados por el simple hecho de mostrar sus simpatías con la candidatura "frente populista" o por manifestar su rechazo a la propaganda de los conservadores" ${ }^{21}$. En Torres, por ejemplo, la Guardia Civil ordenó la recogida de las armas de cazas legalizadas que tenían los campesinos de izquierda, al tiempo que se les amenazaba con no devolvérselas en caso de que no votasen a la candidatura de derechas ${ }^{22}$, mientras que en Alcalá la Real se obligaba a los militantes socialistas a que arrancasen los carteles de propaganda electoral que poco antes ellos mismos habían colocado en las paredes, siendo posteriormente encarcelados ${ }^{23}$,

Sin embargo, donde las coacciones de las derechas alcanzaron sus niveles más escandalosos fue en la provincia de Granada. Ya antes de que se convocaran las elecciones, lo primero que hicieron las gestoras municipales de la coalición radical-cedista fue alterar las listas de electores, eliminando a los ciudadanos de izquierda, mientras rellenaban con nombres ficticios o de muertos los censos de los barrios conservadores ${ }^{24}$. A continuación, desde el Gobierno Civil, se concedieron numerosas licencias de armas a miembros de confianza al servicio de los caciques locales, de manera que en poco tiempo, "la mayor parte de los pueblos estuvieron tomados militarmente por grupos de escopeteros", que durante el día de las votaciones se dedicaron "a cortar el paso, molestar o detener a los electores, apoderados, candidatos y notarios del Frente Popular" ${ }^{25}$.

Antes, en plena campaña, en Padul, tuvo que suspenderse el mitin que tenían previsto celebrar los candidatos socialistas Fernando de los Ríos y Ramón Lamoneda, al ser recibidos a tiros, cuando llegaron al pueblo, por una banda de escopeteros entre los que se encontraban concejales del Ayuntamiento y militantes del Centro Agrario y de Acción Popular. Se denunció también la compra de votos, se detuvieron y se apalearon a los militantes de izquierda, mientras que el llamado Bloque Nacional realizaba su campaña con

20 MORENO GOMEZ, Francisco: La República y la Guerra Civil en Córdoba(1). Córdoba, Ayuntamiento de Córdoba, 1983, pp. 336-339. En Villanueva de Córdoba se cantaría en el carnaval de aquel año, la siguiente copla:

\footnotetext{
"Votaremos a Tolico (Bartolomé Torrico)

que es un hombre muy formal

que nos pagaba los votos

con los puritos de a real"
}

21 COBO ROMERO, Francisco: Labradores, campesinos y jornaleros. Córdoba, Ayuntamiento de Córdoba, 1992, p. 267.

22 Ibídem., p. 268.

23 COBO ROMERO, F.: Conflicto rural y violencia política. Jaén, Universidad de Jaén, 1999, p. 236.

24 LOPEZ MARTINEZ, Mario-GIL BRACERO, Rafael: Caciques contra socialistas. Poder y conflictos en los ayuntamientos de la República Granada, 1931-1936. Granada, Diputación Provincial, 1997, p. 398. Esto ocurría en municipios como Gor, Guadahortuna o Motril.

25 Ibídem., p. 401. 
una gran cantidad de medios y de dinero, sin que faltara el reparto de víveres y ropas entre los campesinos más necesitados a cambio del voto ${ }^{26}$.

Con estos precedentes, el triunfo del Frente Popular en Andalucía fue tan contundente como sorprendente para las derechas. Salvo en Granada, ganaba en todas las provincias. Una victoria mucho más reñida en las provincias de Andalucía oriental, con una fuerte presencia de pequeños propietarios y arrendatarios rústicos ${ }^{27}$, que en la Andalucía occidental, en donde el apoyo otorgado por los militantes anarcosindicalistas de la CNT se había mostrado decisivo en los resultados finales en provincias como Cádiz, Sevilla, Córdoba y Málaga, como ya hemos demostrado en otro lugar ${ }^{28}$.

En el conjunto de Andalucía, 944.505 votos y 62 diputados para el Frente Popular, frente a los 779.837 votos y 29 escaños para el Frente Antirrevolucionario ${ }^{29}$.

Sin embargo, los resultados granadinos serían inmediatamente cuestionados, porque como han demostrado Mario López y Rafael Gil, hubo 113.077 ciudadanos (entre electores y votantes) que padecieron algún tipo de anomalía objetiva, comprobada por actas notariales y por falseamientos evidentes, mientras que la diferencia entre la derecha y la izquierda había sido de poco más de cincuenta mil votos ${ }^{30}$.

Anuladas las elecciones por la Comisión de Actas de las nuevas Cortes, los granadinos serían convocados otra vez a las urnas el 5 de mayo, ya en un contexto político radicalmente distinto ${ }^{31}$.

\section{EL RECRUDECIMIENTO DE LA CONFLICTIVIDAD SOCIAL.}

Después de la represión a la que había sido sometido el conjunto del movimiento obrero durante el anterior bienio "conservador", plasmada en la anulación de las mejoras salariales conseguidas, la clausura de los centros obreros y la persecución o encarcelamiento de sus dirigentes más significados, no podía extrañar que el triunfo de las izquierdas en las elecciones de febrero provocara en los trabajadores un deseo de recuperar todo lo perdido en 1934 y 1935, pero dentro de los cauces del reformismo que caracteriza la política gubernamental de estos meses.

Stanley G. Payne, que se ha acercado al análisis del movimiento huelguístico de este período, ha escrito -para toda España- que sólo en los meses de mayo y junio la actividad huelguística fue tan grande como en todo 1932 o en 1934(menos octubre) y que en los primeros seis meses y medio de 1936 fue mayor que en todo el año 1933, que tenía el record anterior en la historia de España ${ }^{32}$. Unos conflictos, que a diferencia de los de la Fran-

26 Numerosos detalles de estas coacciones en: ibídem., pp. 398-405.

27 A esta cuestión ha dedicado Francisco COBO, su libro: De campesinos a electores. Madrid, Biblioteca Nueva, 2003.

28 CARO CANCELA, Diego: “Abstencionismo y participación electoral en las ciudades de la Andalucía anarquista (1933-1936)”, en: Revista de Estudios Regionales , n 40, 1990.

29 Hemos analizado las causas de la derrota conservadora en estas elecciones, en: CARO CANCELA, Diego: “¿Por qué perdieron las derechas las elecciones de 1936?, en: Revista de Historia Contemporánea, n 9-10, vol. 2, pp. 329-344.

30 LÓPEZ, M. - GIL, R.: op. cit., pp. 426-429.

31 MACARRO, José Manuel: Socialismo, República y revolución en Andalucía (1931-1936). Sevilla, Universidad, 2000, pp. 450-451.

32 El reparto de huelgas por año que ofrece, utilizando como fuente el Boletín del Ministerio de Trabajo de 1936 es el siguiente: 1931(734), 1932(681), 1933(1127), 1934(594), 1935(181), y 1936(1108). Y por meses: enero(26), 
cia del Frente Popular que terminaron en convenios "pragmáticos”, adoptaron -según élun tono más bien "prerrevolucionario", reflejo evidente del carácter esencialmente político de sus motivaciones ${ }^{33}$.

También Burnett Bolloten ha escrito que en los meses que transcurrieron entre las elecciones de febrero y la Guerra Civil, la República experimentó, "tanto en las ciudades como en el campo, una serie de disturbios laborales sin precedentes en su historia" 34 .

Los datos que hemos recogido sobre cinco de las ocho provincias de Andalucía no confirman precisamente estas afirmaciones. Ni el movimiento huelguístico que sigue al triunfo del Frente Popular fue mucho más intenso que el de años anteriores -excepto 1935-, ni las huelgas se caracterizaron por ese tono "esencialmente político" que ellos les asignan.

La mayor parte de los conflictos campesinos de la provincia de Córdoba de estos meses, por ejemplo, tuvieron al paro obrero como problema de fondo y se hicieron para reivindicar mejores bases de trabajo, después del hundimiento de los salarios en el bienio anterior $^{35}$. Lo mismo ocurría en Cádiz o en la provincia de Granada, donde según el estudio de José Antonio Alarcón, las "huelgas salariales" fueron las que ocuparon el primer lugar, representando la mitad de los conflictos producidos en 1936, mientras que sólo de una de las 20 huelgas planteadas podía decirse que tuvo una motivación marcadamente política $^{36}$.

Pero el mejor desmentido a esta tesis lo ofrece el estudio que José Manuel Macarro ha realizado sobre Sevilla, llamada la "roja", por la intensa agitación social que padeció en estos años de la Segunda República. Si. entre 1931 y 1934 fueron 14 las huelgas generales convocadas en la ciudad, bien por la CNT, bien por la Unión Local de Sindicatos vinculada al PCE, en 1936. no hubo ninguna y los 13 conflictos parciales que se produjeron tuvieron las siguientes motivaciones: bases de trabajo, 2; defensa de las bases de trabajo, 1 ; horario, 2; condiciones de trabajo, 1; solidaridad: a)despedido, 1;b)interna, 1; c)con otro gremio, 1 ; societarias(defensa sindical), 1 ; de ámbito nacional, 1 ; desconocida, $2^{37}$. Incluso Fernando Pascual llega a escribir sobre el conjunto de la provincia:

"Durante 1936 el número de huelgas volvió a incrementarse aunque no llegó al nivel de los cuatro primeros años. Los conflictos fueron de escasa duración e intensidad. Sin embargo, la patronal reaccionó amplificando los temores de la derecha a las consecuencias que pudieran derivarse del triunfo del Frente Popular" 38 .

febrero(19), marzo(47), abril(105), mayo(242), junio(444) y julio(225). Vid. La primera democracia española. Barcelona, Paidos, 1995, p. 379.

33 Ibídem., pp. 378-379.

34 BOLLOTEN, Burnett: El gran engaño. Las izquierdas y su lucha por el poder en la zona republicana. Barcelona, 1975, p. 18. Sobre este libro, nos remitimos a las referencias bibliográficas incluidas en la nota 3.

35 MORENO GOMEZ, Francisco: op. cit., pp. 381-389.

36 ALARCON CABALLERO, José Antonio: El movimiento obrero en Granada en la II República (1931-1936). Granada, Diputación Provincial, 1990, p. 421.

37 MACARRO, José Manuel: La Utopía revolucionaria. Sevilla en la Segunda República. Sevilla, Caja de Ahorros y Monte de Piedad de Sevilla, pp. 85-92.

38 PASCUAL CEVALLOS, Fernando: Luchas agrarias en Sevilla durante la Segunda República. Sevilla, Diputación Provincial, 1984, p. 102 
Pero que las huelgas no tuvieran una motivación política no significa que el nuevo contexto que abrió las elecciones del Frente Popular no tuviera nada que ver con esta conflictividad. Era evidente que la llegada al Gobierno de una coalición política que ellos habían apoyado y a los Ayuntamientos -como alcaldes y concejales- de muchos de sus líderes, fue entendido por los trabajadores como el momento más propicio para plantear unas reivindicaciones hasta entonces postergadas o reclamar la recuperación de las conquistas sociales alcanzadas en los dos primeros años de República.

CUADRO I. LAS HUELGAS EN ANDALUCÍA (1931-1936) ${ }^{39}$

\begin{tabular}{|c|c|c|c|c|c|c|}
\hline & 1931 & 1932 & 1933 & 1934 & 1935 & 1936 \\
\hline Cádiz(prov.) ${ }^{40}$ & 42 & 58 & 36 & 55 & 3 & 23 \\
\hline Córdoba(prov.) ${ }^{41}$ & 81 & 48 & 113 & 58 & 3 & 38 \\
\hline Granada(prov.) ${ }^{42}$ & 69 & 73 & 41 & 7 & 2 & 20 \\
\hline Jaén(prov) ${ }^{43}$ & 94 & 174 & 237 & 144 & 7 & 46 \\
\hline Sevilla(cap.) ${ }^{44}$ & 67 & 23 & 27 & 9 & 4 & 13 \\
\hline Sevilla(prov. $)^{45}$ & 48 & 75 & 60 & 32 & 1 & 22 \\
\hline
\end{tabular}

\section{LA REAPARICIÓN DEL ANTICLERICALISMO}

Pero más que esta conflictividad huelguística, lo que verdaderamente sorprende de la primavera de 1936 es la magnitud que alcanzan los brotes anticlericales y los actos de violencia política, síntomas de dos factores que aparecen íntimamente relacionados. El primero, sin duda, era el poso de rencor que generó en las clases populares la política reaccionaria aplicada por la coalición radical-cedista en el bienio que estuvieron gobernando. Sin considerar las humillaciones y las privaciones que los trabajadores padecieron en este período, no se puede comprender el clima de odio que acompaña a algunas de las violentas acciones que se producen tras el triunfo del Frente Popular.

Lo que faltó para encender la "mecha" fueron las provocaciones patronales y de los grupos armados de extrema derecha; de aquí que cuando éstas se produjeron, la situación se hiciera verdaderamente explosiva. Este segundo factor, por ejemplo, es el está detrás del acontecimiento más violento que ocurre en la provincia de Córdoba durante la Segunda República, en el municipio de Palma del Río, durante los días 19 y 20 de febrero, esto es, tres días después de la victoria izquierdista.

39 En el año 1936 sólo se contabilizan las huelgas producidas hasta el 18 de julio.

40 CARO CANCELA, Diego: "Una aproximación cuantitativa a los conflictos obreros en la provincia de Cádiz durante la Segunda República”, en: Cádiz en su historia. V Jornadas de Historia de Cádiz. Cádiz, Caja de Ahorros de Cádiz, 1986, p. 131

41 MORENO GOMEZ, Francisco: op. cit., p. 313.

42 ALARCON CABALLERO, José Antonio: op. cit., pp. 339-440. Hay que advertir que el bajo número de huelgas del año 1934 se debe a que se contabiliza como única la huelga general la que a principios de junio convocó la FNTT de la UGT y que se extendió por más de medio centenar de municipios de la provincia.

43 GARRIDO GONZALEZ, Luis: Riqueza y tragedia social. Historia de la clase obrera en la provincia de Jaén (1820-1939). Jaén, Diputación Provincial, 1990, tomo II, p. 453.

44 MACARRO, José Manuel: op. cit.., p. 85.

45 PASCUAL CEVALLOS, Fernando: op. cit., p. 99. 
Por lo que se sabemos, todo comenzó cuando en la noche del día 19 desde el círculo de Acción Popular partieron unos disparos que alcanzaron a unos obreros que pasaban por la calle. No pudiéndose encontrar a los autores de los mismos, a continuación se formaba una multitudinaria manifestación que terminaba apedreando el centro derechista.

Pero los hechos más graves se producían a la mañana siguiente, cuando grupos de jornaleros acompañados por sus mujeres e hijos se echaban a la calle ${ }^{46}$. Lo primero que hacían era asaltar el citado centro de la CEDA y el del Partido Radical, destruyendo e incendiando su mobiliario en la calle. A continuación, pasaban a la plaza del Ayuntamiento, destrozando también todo el mobiliario y la documentación de la Administración de Arbitrios y, poco después, eran asaltadas once casas de los más ricos propietarios agrícolas de la población. Pero si ya estos incidentes fueron graves, más repercusión tuvo la quema de iglesias y conventos que le acompañaron. Era destruida la parroquia de la Asunción, sus catorce altares, el archivo, el órgano y el coro. Igual suerte corría el convento de San Francisco, donde además fue profanado el panteón de una de las adineradas familias locales, el convento de Santo Domingo y el de Santa Clara, ambos del siglo XVI, todo ello ante la pasividad de las fuerzas de la Guardia Civil, que se limitaron a contemplar las acciones de los revoltosos ${ }^{47}$.

Este mismo tono anticlerical tuvieron los sucesos que pocos días después, el 8 de marzo se producían en Cádiz, al término de una gran manifestación obrera organizada conjuntamente por los principales sindicatos locales -la UGT y la CNT-, para presentar a las autoridades una plataforma conjunta de reivindicaciones sociales. Terminada la misma sin ningún tipo de incidentes, grupos de jóvenes asaltaban el colegio de San Felipe Neri con el pretexto de que en él se ocultaba un depósito de armas, continuando los destrozos en otros edificios religiosos, hasta que la intervención del Ejército -ya por la tarde-puso fin a los desmanes ${ }^{48}$. EL balance final de los incidentes era catorce edificios asaltados o incendiados, un muerto por arma de fuego durante la carga policial ante la residencia de las Esclavas y diversos heridos y contusionados.

Al día siguiente, 9 de marzo, los graves altercados tenían lugar en Granada, después que un grupo de pistoleros falangistas abriera fuego contra una reunión de familias trabajadoras que tenía lugar en la plaza del Campillo, con el resultado de varios heridos ${ }^{49}$. La respuesta de las organizaciones obreras se plasmaba en la convocatoria, al día siguiente, de una huelga general masivamente seguida y en la que se producían "los incidentes más graves que se conocieron en la ciudad a lo largo de la República"50. Grupos de trabajadores incendiaban por la mañana el local de Falange, el teatro "Isabel la Católica", dos cafés, el diario "Ideal", los locales de AP y de Acción Obrerista, una fábrica de chocolates propiedad de un conocido miembro de la CEDA, varias tiendas y domicilios de familias derechistas, el pabellón del tenis-club y varias iglesias del barrio de Albaicín: el convento de San Gregorio Bajo y San Gregorio Alto, la iglesia del Salvador y la de San Cristó-

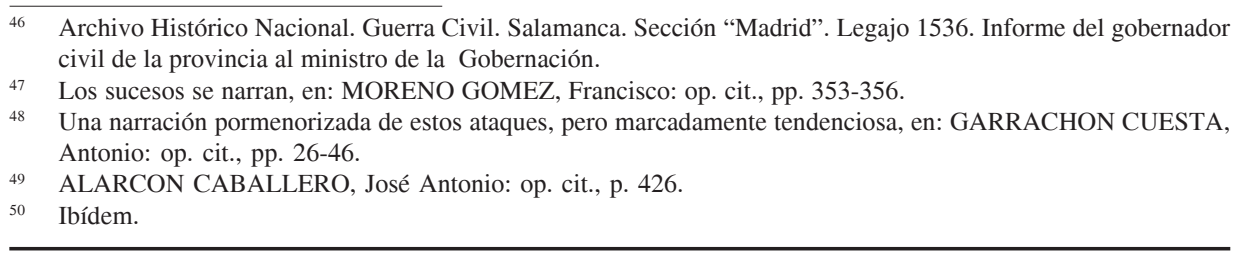


bal. Todo ello, mientras que el cruce de disparos entre huelguistas y elementos fascistas provocaba al menos dos muertos y veinte heridos.

\section{CUADRO II. EDIFICIOS RELIGIOSOS ASALTADOS Y/O DESTRUIDOS}

\begin{tabular}{|l|c|c|c|c|c|c|c|c|c|}
\hline & AL & CA & CO & GR & HU & JA & MA & SE & TOTAL \\
\hline Febrero & & & 5 & 1 & & & 7 & 5 & 19 \\
\hline Marzo & 1 & 11 & 1 & 4 & 4 & 1 & 7 & & 29 \\
\hline Abril & & 6 & & 2 & & & & 3 & 11 \\
\hline Mayo & & & 1 & & 1 & & 1 & 3 & 6 \\
\hline Junio & & & & & & & & 1 & 1 \\
\hline Julio & & & & & & & & & \\
\hline TOTALES & 1 & 17 & 7 & 7 & 5 & 1 & 16 & 12 & 66 \\
\hline
\end{tabular}

AL=Almería; $\mathrm{CA}=$ Cádiz; $\mathrm{CO}=$ Córdoba; $\mathrm{GR}=\mathrm{Granada} ; \mathrm{HU}=$ Huelva; JA=Jaén; MA=Málaga; $\mathrm{SE}=$ Sevilla.

De estas y otras agresiones anticlericales que por estas semanas se producen en distintos puntos de Andalucía llama la atención dos circunstancias. La primera es la amplitud espacial y temporal que alcanza. No estamos como en 1931, cuando los altercados apenas duraron un par de días y se localizaron en las provincias de Málaga, Sevilla y Cádiz, con el resultado de 58 edificios atacados o incendiados total o parcialmente ${ }^{51}$. Ahora, sin embargo, son 66 y como en 1931, Málaga, Sevilla y Cádiz aparecen a la cabeza de esta fobia anticatólica $^{52}$

La otra circunstancia que debe destacarse es la ausencia total de ataques personales a los miembros del clero, algo que no había ocurrido en la Asturias de octubre del 34, ni ocurrirá en la Guerra Civil.

¿Qué explicación tiene a la altura de 1936 la revitalización de este sentimiento anticlerical?. Creemos que hay ponerlo en relación, en primer lugar, con la identificación que se seguía manteniendo en los sectores populares de las instituciones religiosas con los grupos social y económicamente dominantes. Una identidad que se acentuó en el bienio conservador, cuando fue claramente perceptible la importante tarea que miembros del clero habían tenido en la reconstrucción de la derecha católica aglutinada alrededor de la CEDA.

De la identificación se pasó a la animadversión cuando la izquierda española -especialmente los socialistas- vieron en la CEDA el verdadero peligro fascista en España, después de lo que había ocurrido en Austria en febrero de 1934, donde un partido de inspiración católica es el que aplasta al movimiento obrero. De esta manera, El Socialista, por

51 ROBINSON, Richard: Los orígenes de la España de Franco. Derecha, República y Revolución, 1931-1936. Barcelona, Grijalbo, 1974, p. 59. En Málaga sólo fueron 41.

52 El recuento comprende sólo hasta el 17 de julio de 1936: FUENTE: Historia de la Cruzada Española. Madrid, Ediciones Españolas, 1940, volumen segundo, tomo noveno, pp. 444-525. Archivo Histórico Nacional. Sección Guerra Civil. Salamanca. Político Social. Serie "Madrid”, Legajo 1536. Informes de los gobernadores civiles al ministro de la Gobernación sobre alteraciones de orden público. Esta documentación sólo recoge los incidentes producidos en las provincias de Almería, Córdoba, Granada, Jaén, Málaga y Sevilla, y sólo los producidos en los meses de febrero y marzo de 1936. Estas dos fuentes se ha completado con la bibliografía citada a lo largo del trabajo. Agradezco al profesor Leandro Alvarez que me facilitara una copia de la documentación procedente del Archivo Histórico Nacional de Salamanca. 
ejemplo, no se cansaba de escribir sobre lo que llamaba el "clerical-fascismo", convirtiéndose el catolicismo y el fascismo en las dos caras de una misma moneda para el discurso izquierdista ${ }^{53}$.

Este rechazo se acentuó por la política antiobrera practicada por la coalición radicalcedista y por la nada disimulada participación de miembros concretos del alto clero en la campaña electoral de febrero, pidiendo el voto para la candidaturas contrarrevolucionarias $^{54}$. Sólo desde esta connivencia -a veces descarada- del clero con las derechas puede explicarse la rápida intransigencia de las nuevas autoridades locales contra los actos religiosos, nada más formarse las gestoras frentepopulistas y la ira con que fueron atacados al mismo tiempo, edificios religiosos, centros políticos de la CEDA o el Partido Radical y los casinos de reunión y ocio de la oligarquía terrateniente y los propietarios locales, como ocurrió en Palma del Río, en Cádiz, en Granada y en otros municipios concretos de la región.

\section{LA VIOLENCIA POLÍTICA}

Julio Gil Pecharromán ha escrito que, "la violencia es, sin duda, el rasgo más destacado de la vida nacional entre febrero y julio de 1936 y el que contribuyó de un modo más patente al progreso de la opción golpista de la derecha" ${ }_{55}$. Y es que si huelgas y brotes de anticlericalismo habían sido manifestaciones de conflictividad social que ya se habían producido desde el mismo momento de la proclamación del régimen republicano, lo que realmente resultaba novedoso en esta primavera de 1936 es el incremento que alcanza la violencia política, limitada en el primer bienio republicano a las acciones armadas de los anarquistas Comités de Defensa o a algún que otro pistolero vinculado al Partido Comunista. Ahora lo que se producía era un enfrentamiento triangular en el que participan militantes de izquierdas contra patronos o militantes de derechas, de ambos contra las fuerzas de orden público y lo que resultaba más sorprendente: entre los propios militantes de la izquierda política y obrera.

Como ya se ha señalado al principio, este fenómeno no era privativo de Andalucía, ni siquiera de España, porque ya venía produciéndose en las calles de otros países europeos desde principios de años veinte. Detrás de lo que Julio Aróstegui ha llamado la “militarización de la política" en la Segunda República hay que distinguir hasta cuatro factores: $1 \%$ Una movilización social sin precedentes, que tiene como consecuencia más inmediata un importante incremento de la afiliación a todo tipo de organizaciones políticas, sindicales y patronales ${ }^{56}, 2 \%$ Una relevante incorporación de la juventud a la vida política y social, proporcionando numerosos y nuevos militantes a las organizaciones juveniles de partidos y sindicatos ${ }^{57}, 3^{\%}$ Una fuerte confrontación social entre propietarios y

53 DE LA CUEVA MERINO, Julio: "El anticlericalismo en la Segunda República y la Guerra Civil”, en: LA PARRA, Emilio-SUAREZ, Manuel: El anticlericalismo español contemporáneo. Madrid ,Biblioteca Nueva 1998, p. 250.

54 La circular lanzada por el obispo de Córdoba el 27 de enero, por ejemplo, se comenta por sí sola. Se reproduce parcialmente en: MORENO GÓMEZ, Francisco: op. cit., pp. 334-335.

55 GIL PECHARROMAN, Julio: La Segunda República. Madrid, Historia 16, 1989, p. 188.

56 Sobre esta numerosa militancia en partidos y sindicatos, vid.: CARO CANCELA, Diego: Violencia política...pp. 108 y ss. ; MACARRO, José Manuel.: op. cit., pp. 45-66.

57 De esta cuestión se trata en el número monográfico que dedica Studia Histórica. Historia Contemporánea a los "Movimientos juveniles en la España contemporánea", Salamanca, no 4 (1987). 
trabajadores por las medidas contenidas en el proyecto reformista, tales como la reforma agraria, la laicización de la educación, la separación Iglesia-Estado o la política social del Gobierno republicano-socialista, y 4\% La creación de distintos tipos de estructuras paramilitares dentro de las organizaciones políticas y sindicales del momento: "Primera Línea" de Falange, las Milicias Obreras y Campesinas del PCE, los Comités de Defensa de la CNT-AIT, el Requeté carlistas o las propias milicias socialistas ${ }^{58}$.

No es, por tanto, la violencia política algo que tenga que ver con las peculiaridades temperamentales o genéticas de los españoles o los andaluces, como dijeron los propagandistas del franquismo y algún que otro intelectual de la época, sino con la crisis social y política que padece el sistema liberal en la Europa de entreguerras. En el contexto de lo que antes llamábamos la "guerra civil europea", lo que ocurre en la primavera de 1936 está relacionado también, en primer lugar, con el resultado de las elecciones de febrero y lo que suponía de fracaso de la "vía legalista" que había defendido la dirección de la CEDA para conquistar y mantener el Poder. Esta circunstancia dio alas a los sectores más extremistas de la derecha -la integrada por falangistas, carlistas y monárquicos alfonsinos-, partidarios desde siempre de la "vía insurreccional" y armada para acabar con el régimen republicano. No lo podía expresar mejor uno de sus periódicos, el Diario de Jerez, vinculado a la Comunión Tradicionalista:

"Las Derechas-mejor dicho, los españoles-tienen que ir pensando en otra cosa. Con las elecciones no se arregla esto y si se vuelven a convocar, hay además el peligro de que nadie vote; porque este straperlo conocido por sufragio inorgánico, a nadie convence ${ }^{59}$.

Por otra parte, la división y la radicalización de una parte importante del movimiento socialista, el liderado por Francisco Largo Caballero y asentado sobre la UGT y las Juventudes Socialistas (JJ. SS), también favoreció la creación de estructuras paramilitares en este sector del movimiento obrero en el que estas prácticas no tenían ninguna tradición ${ }^{60}$.

Pero antes que la violencia física estaba la violencia verbal, que venían practicando todos los dirigentes políticos, excepto los republicanos y que en la campaña electoral de principios de 1936 había alcanzado cotas difícilmente superables, con todo tipo de insultos, amenazas y descalificaciones al adversario político. En Rutas, el órgano de expresión de la Juventudes de Acción Popular de Cádiz, por ejemplo, se decía lo siguiente sobre varios periódicos madrileños, a las que de paso se calificaba de "prensa prostituida y enfangada":

"Ahora chillan y gallean más que nunca porque saben que tienen poca vida. El JEFE los hará callar para siempre. Para poder lograrlo VOTAD A ESPAÑA" ${ }^{61}$.

8 AROSTEGUI, J.: "La militarización de la política durante la II República", en: Historia Contemporánea, n 11 (1994), pp. 13-24.

59 Diario de Jerez (19 febrero 1936).

60 GIBAJA VELAZQUEZ, José Carlos. "La tradición improvisada: el socialismo y la milicia", en: Historia Contemporánea, $\mathrm{n}^{\circ} 11$ (1994), pp. 107-127.

61 CARO CANCELA, Diego: La Segunda República en Cádiz: elecciones y partidos políticos. Cádiz, Diputación Provincial, 1987, p. 245. 
Incluso el exministro de la CEDA, Federico Salmón, en el mitin que inauguraba la campaña de esta formación en Cádiz, el 29 de diciembre de 1935, afirmaba sobre el resultado final de las elecciones:

\section{“Si ellos triunfan, nos aplastarán; si nosotros triunfamos, les aplasta- remos" 62 .}

Las izquierdas de Jerez, mientras tanto, escribían en su periódico que las derechas eran las que "asesinaban" a traición, porque mataban de hambre al pueblo trabajador, acusándolas también de ser "los cobardes, incubadores de la tuberculosis, de la anemia, del tifus, de todas las enfermedades hijas del régimen político y social sostenido por Gil Robles y sus bandas" $" 63$.

Caldeado el ambiente por las palabras, las acciones armadas no tardarían en llegar después del triunfo del Frente Popular. Es muy difícil conocer con exactitud todos los incidentes provocados por la violencia política en este período, si tenemos en cuenta la censura de prensa que estableció el Gobierno republicano sobre los altercados de orden público. De esta manera, sólo se publicaron las estadísticas generales que los líderes derechistas Gil Robles y Calvo Sotelo presentaron en sus discursos parlamentarios, con la intención de acusar de debilidad al Gobierno, culpándolo del creciente desorden público. Unas cifras exageradas porque mezclaban la violencia política con delitos comunes, incluyendo todo tipo de incidentes que sirvieran para engordar los números que dieron ${ }^{64}$.

Más recientemente, Ramiro Cibrián ha estudiado detalladamente esta cuestión. Utilizando fuentes hemerográficas -los diarios El Sol de Madrid y La Nación y La Prensa de Buenos Aires- su investigación ha calculado un total de 773 homicidios políticos del 31 de enero al 17 de julio de 1936 en toda España, que representan un 20 por ciento menos que las cifras que en su día presentó Gil Robles ${ }^{65}$.

La oleada más importante de incidentes mortales se produce en el primer mes después del triunfo del Frente Popular y se redujo tras la ilegalización de la Falange a mediados de marzo. Volvió a subir a mediados abril, para alcanzar sus mayores niveles hacia finales de mayo, en una tensión que se mantendría ya hasta el comienzo de la Guerra Civil.

En cuanto a la distribución geográfica, Madrid aparece en el primer lugar por el número de muertes causadas por la violencia política, seguida de Sevilla(ciudad y provincia), Cádiz y Málaga(ciudad y provincia), mientras que Cataluña sería una de las regiones donde la violencia política alcanzó sus cotas más bajas ${ }^{66}$. Y buscando un modelo interpretativo que explique este desigual reparto de la violencia o por qué ésta es más intensa en unas zonas que en otra, Cibrián la pone en relación con tres varia-

\footnotetext{
Ibídem.

Ibídem., p. 313. El artículo se titulaba “¡Cobardes!. Asesináis a traición”.

REIG TAPIA, A.: Violencia y terror...,pp. 28-29.

CIBRIAN, Ramiro: "Violencia política y crisis democrática: España en 1936", en: Revista de Estudios Políticos, no 6 (1978), pp. 81-115. Y también: CRUZ, Rafael: En el nombre del pueblo. Madrid, Siglo XXI editores, 2006. 66 Ibídem., p. 113.
} 
bles: la "Fuerza Socialista Institucionalizada" ción" 69 .

Con estos datos y los que proporciona Juan Linz en uno de sus trabajos ${ }^{70}$ y comparándolos con los que recoge de otros países europeos, Stanley G. Payne ha concluido que, "la violencia política fue en España proporcionalmente más grave que la de las luchas intestinas producidas antes del derrumbe de la democracia en Italia, Alemania y Austria, con la posible excepción de los primeros meses de semiguerra civil en la República de Weimar en 1918-1919"'71.

Las informaciones que hemos podido recoger sobre las muertes causadas por la violencia política en Andalucía nos permiten matizar algunas de las conclusiones generales que estos investigadores han establecido para el conjunto de España. En primer lugar, hay que señalar el carácter provisional de las estadísticas hemerográficas, dada la censura de prensa que existió sobre estos asuntos durante muchas semanas. Mientras no se consulten otro tipo de fuentes -municipales o provinciales- no tendremos el marco completo de este problema. Por ejemplo: en la provincia de Cádiz los dos sucesos violentos más graves que ocurrieron estos meses, en Jerez ${ }^{72}$ y Alcalá del Valle, con tres muertes violentas y numerosos heridos no se llegaron a recoger en la prensa provincial.

En segundo lugar es difícil encontrar un único modelo interpretativo capaz de explicar la amplia casuística que tiene la violencia política de esta primavera en Andalucía. Desde luego, no guarda relación con la implantación socialista, como afirma Ramiro Cibrián, porque provincias como Jaén o Huelva donde ésta era importante son las que presentan los índices más bajos de violencia política. Más vinculación puede tener con la implantación de la CNT y su rivalidad con otras organizaciones obreras de corte socialista, comunista o con la propia extrema derecha. En tercer lugar, llama la atención que lejos de ir creciendo, como en el resto de España, las muertes por violencia política dejan de producirse en Andalucía desde mediados de junio, esto es, desde un mes antes que estallara la Guerra Civil. Y, por último, lo que resulta verdaderamente sorprendente es la falta de sensibilidad con que parte de la izquierda política y obrera presenció esta práctica de la violencia, sin valorar las negativas consecuencias que podía tener para la estabilidad del sistema democrático republicano.

CUADRO III. MUERTES CAUSADAS POR LA VIOLENCIA POLÍTICA ${ }^{73}$

\begin{tabular}{|l|c|c|c|c|c|c|c|c|c|}
\hline & AL & CA & CO & GR & HU & JA & MA & SE & TOTAL \\
\hline Febrero & 2 & & & & & & 2 & 1 & 5 \\
\hline Marzo & & & & 3 & & 1 & & 2 & 6 \\
\hline Abril & 1 & 1 & 1 & & & 1 & & 4 & 8 \\
\hline Mayo & & 2 & 1 & 2 & 1 & & & 1 & 7 \\
\hline Junio & & & 2 & & & & 3 & 1 & 6 \\
\hline TOTAL & 3 & 3 & 4 & 5 & 1 & 2 & 5 & 9 & 32 \\
\hline
\end{tabular}

\footnotetext{
Que se mediría por el porcentaje de votos estimados para el PSOE en las elecciones de febrero.

68 Que se calcula por medio de la implantación comunista y falangista en cada distrito electoral, medida por el número de candidatos presentados y/o elegidos.

69 Que se mide sumando los porcentajes de votos obtenidos por todos los partidos de izquierda y derecha.

70 LINZ, Juan: "From Great Hopes to Civil War: The Breakdown of Democracy in Spain", en: The Breakdown of Democracy Regimen: Europe. Baltimore, 1978, p. 188, citado en: PAYNE, Stanley G.: op. cit.., p. 403.

71 PAYNE, Stanley G.: op. cit.

72 Lo contamos con detalle, en: CARO CANCELA, Diego: Violencia política...pp. 439-441.

73 FUENTE: Las que se citan en el CUADRO II.
} 
Si el ejercicio de la violencia por parte de la extrema derecha era algo previsible en sus continuos intentos por desestabilizar el régimen democrático, creando una situación de desorden social que justificara la acción de los militares golpistas, no se entiende bien, por el contrario, la pasividad de muchos dirigentes izquierdistas en cortar unas prácticas que sólo servían para poner en cuestión al Gobierno frentepopulista y su debilidad ante la opinión pública, haciendo bueno el discurso conservador de que República era igual a caos. Como en otras cuestiones, fue el dirigentes socialista Indalecio Prieto el que mejor percibió el daño que este ambiente le creaba a la democracia republicana. En un mitin en el que intervino en Cuenca, a primeros de mayo, con motivo de la repetición de las elecciones en esa provincia, diría con tono premonitorio:

“...los españoles de hoy no hemos sido testigos jamás, ijamás! de un panorama tan trágico, de un desquiciamiento como el que España ofrece en estos instantes (...).

La convulsión de una revolución, con un resultado u otro, la puede soportar un país. Lo que no puede soportar un país es la sangría constante del desorden público sin una finalidad revolucionaria inmediata; lo que no soporta una nación es el desgaste de su Poder público y de su propia vitalidad económica manteniendo el desasosiego, la zozobra y la intranquilidad. Podrán decir espíritus simples que este desasosiego, esta zozobra, esta intranquilidad la padecen sólo las clases dominantes. Eso a mi juicio constituye un error. De ese desasosiego, de esa zozobra y de esa intranquilidad no tardará en sentir los efectos perniciosos la propia clase trabajadora a virtud de trastornos y posibles colapsos de la economía, porque la economía tiene un sistema a cuya transformación aspiramos, pero que mientras subsista hemos de atenernos a sus desventajas, y entre ellas ésta: la de que refleja dolorosamente sobre los trabajadores la alarma, el desasosiego y la intranquilidad de las clases dominantes(...).

Eso es colaborar con el fascismo. Porque el fascismo necesita de ese ambiente. El fascismo, aparte aquellos núcleos alocados que puedan ser sus agentes ejecutores(...) por sí no es nada, si no se le suman otras zonas más vastas del país, entre las cuales pueden figurar las clases medias y la pequeña burguesía que viéndose atemorizada a diario y sin adivinar en el horizonte una solución salvadora, pudieran sumarse al fascismo (...)" ${ }^{74}$.

Pues bien, mientras que Prieto tenía esta visión de la realidad, su rival en controlar la dirección del PSOE, Largo Caballero despachaba los rumores que le llegaban sobre un posible pronunciamiento militar con los siguientes comentarios:

"si se quieren proporcionar el gusto de dar un golpe de Estado por sorpresa, que lo den (...). A la clase obrera no se la vence(...) No conseguirán más que disfrutar unos días o unos meses de la satisfacción que pueda

74 El Socialista (2 mayo 1936). También en: Historia de la Cruzada Española., volumen segundo, tomo noveno, p. 493. 
proporcionarle el mando. Porque no quiero suponer que nos vayan a cortar a todos las cabezas (risas)" 75

Y es que la imagen que presentaba la vida política en la primera mitad del año 1936 no era precisamente la de dos Españas divididas irreconciliablemente que se crearía después, sino la de la profunda fragmentación interna por la que pasaban los dos grandes partidos del momento -la CEDA y el PSOE ${ }^{76}$ - y también la propia CNT.

En el caso del PSOE esta ruptura alcanzaría su máxima manifestación pública en los llamados "sucesos de Ecija", cuando los "caballeristas" interrumpieron a tiros el mitin que estaba dando Indalecio Prieto y dos de los líderes de la revolución asturiana del 3477. Mientras, la CNT se debatía entre los partidarios de avanzar hacia la unidad con la UGT, como en $\mathrm{Cádiz}^{78}$ y los que preferían resolver a tiros sus diferencias con los ugetistas, como ocurría en Málaga en los sucesos de mediados de junio, sin duda el momento en el que la violencia política alcanzó su cénit en Andalucía antes de que estallara la Guerra Civil.

El origen de los hechos estuvo en la declaración de huelga hecha el 9 de junio por los obreros de los saladeros de pescados del puerto de Málaga, afectos a la CNT, mientras que los vinculados a la UGT acudían al trabajo. Al día siguiente, cuando a las cinco y media de la mañana salía de su casa el presidente del Sindicato de los pescadores ugetistas, el concejal comunista Andrés Rodríguez, éste era tiroteado por tres desconocidos, sin darle tiempo a sacar la pistola que llevaba.

No habían pasado tres horas cuando otros tres individuos acudían a la casa del presidente del Sindicato Único del Ramo de la Alimentación de la CNT, que sufría un atentado, a pesar de tener su hija pequeña en brazos, quedando gravemente herido ${ }^{79}$.

Después de estas dos agresiones, la tensión en la ciudad alcanzaba su máximo nivel cuando grupos de uno y otro bando se enfrentaban -pistola en mano- en la calle Ancha a las nueve de la mañana, dejando un transeúnte herido con un balazo en la pierna.

Más tarde, varios desconocidos lanzaban un botella con líquido inflamable en el local de la CNT, trasladándose posteriormente a los locales de la Escuela Racionalista, donde destrozaban todos sus muebles. En respuesta, otro grupo contrario atacaba la Casa del Pueblo.

A las diez de la mañana el paro era completo en la ciudad por la orden de huelga general lanzadas separadamente por la UGT y la CNT.

El 11 de junio, amanecía en Málaga con el entierro del edil comunista, acompañado por un cortejo fúnebre en el que participaban -en perfecta formación- las Juventudes Socialistas Unificadas, vistiendo pantalones azules, camisas azules o rojas y corbatas rojas. Pues bien, cuando salía de su domicilio para dirigirse al funeral sufría otro atentado y que-

75 Discurso de Largo en la clausura del congreso de la Federación local (ugetista) de la edificación de Madrid. Claridad (27 junio 1936), citado en: JULIA, S.: La izquierda del PSOE (1935-1936). Madrid, Siglo XXI, 1977, p. 282.

76 JULIA, Santos.: "España sin guerra civil.¿Qué hubiera pasado sin la rebelión militar de julio de 1936", en: FERGUSON, Niall (ed): Historia virtual. Madrid, Taurus, 1998, p. 199.

77 Lo cuenta MACARRO, en: op. cit., pp. 432-433. También, en: Socialismo, República..., pp. 452-462.

78 GUTIERREZ MOLINA, José Luis. : Crisis burguesa y unidad obrera. El sindicalismo en Cádiz durante la Segunda República. Madrid, Nossa y J., 1994, pp. 411-435.

79 La narración de estos hechos procede de un informe mecanografiado, sin firma, que se conserva en el Archivo Díaz Escobar, con el título de "Anales de 1936", que nos parece bastante fiable. Colección de folletos y hojas sueltas. Caja no 319 (6). Málaga. 
daba herido de muerte el presidente de la Diputación y vicepresidente de la Agrupación Provincial Socialista, Antonio Román Reina.

Con este ambiente, al mediodía, un tiroteo que partía de un coche en marcha, con matrícula de Sevilla - ¿ eran pistoleros llamados de fuera ? - provocaba la muerte de una niña que jugaba en la calle con una bala en el cuello y dejaba herida a su hermana que la acompañaba. Y a las cinco de la tarde, también era tiroteado sin consecuencias otro concejal comunista.

Al día siguiente, 12 de junio, a las siete de la mañana, era asesinado otro obrero cenetista después de ser sacado del bar donde estaba por tres jóvenes que le disparaban trece balazos. Horas después, se celebraba el entierro del presidente de la Diputación con la presencia de un inmenso gentío y representaciones de todas las sociedades obreras afectas a la UGT y el PCE.

Es en esta fragmentación interna de la izquierda, en la falta de un proyecto político compartido por los partidos firmantes del Frente Popular para mantener el sistema democrático frente a sus enemigos, en la irresponsabilidad con la que algunos dirigentes políticos toleraron la violencia practicada por sus seguidores donde hay que buscar las causas del deterioro de la vida política, más que en la polarización de la sociedad o el ascenso de los extremismos políticos, como el falangismo o el comunismo todavía muy débilmente implantados a la altura del verano de 1936. Fueron estos los factores que crearon el caldo de cultivo apropiado para que los golpistas pudieran seguir con sus planes trazados de antemano y captando más voluntades cada día que pasaba. Por tanto, el fracaso de la República no estuvo en los problemas estructurales o coyunturales de la sociedad española que tampoco ayudaron-sino en la ineptitud de las élites políticas del momento -de la derecha y de la izquierda- incapaces por su imprevisión de frenar a unos militares sublevados que enterraron en sangre la experiencia más democrática que hasta entonces había vivido la España del siglo $\mathrm{XX}^{80}$.

80 Un buen análisis de las causas del fracaso de la República, en: PAYNE, S. G.: o p. cit., pp. 415-428. Menos ecuánime nos parece su último libro: El colapso de la República. Madrid, La Esfera de los Libros, 2005. 